\title{
Research on the "Three Networks in One" Orchard Production Information Service System
}

\author{
Yun Qiu, Jingchao Fan, Lin Hu, and Guomin Zhou \\ Agricultural Information Institute (AII) of the Chinese Academy of Agricultural Sciences \\ (CAAS), Beijing 100081 \\ qiuyun@mail.caas.net.cn
}

\begin{abstract}
This system has, by the comprehensive use of various latest information technologies and active gateway technologies, linked the wireless communication network, fixed-line telephone network and the Internet network (Three Networks) together to realize the seamless bridging of information, so as to broaden the service scope of the application system on the internetwork. The agricultural experts and/or agricultural technology promoters could provide the information service to the grassroots orchardists by use of this system in an even more convenient and speedy manner and the grassroots orchardists could also obtain the information on the internetwork in a flexible and convenient form, so that the "problem of last kilometer" in the dissemination of orchard information has been effectively solved.
\end{abstract}

Keywords: information technology, orchardist hotline, orchard production, remote diagnosis, last kilometer.

\section{Proposition of the Problems}

Since our implementation of the reform and opening-up policies, China's orchard production has seen a rapid development. In 2010, China's fruit cultivation area reached 11.5440 million hectares and the output thereof achieved 214.0140 million tons [1]. China's fruit production has ranked the first place in the world [2]. However, there also exist some problems, which have restricted the healthy and sustainable development of the orchard industry. The first is the poor quality and low ratio of high-quality fruits. At present, China's ratio of high-quality fruits is less than $10 \%$ of the total output and the top-grade fruits up to the export standard is less than $5 \%$ of the total output [3], which has resulted in the low market competition and low benefit. The second is the backward sustainable development of the orchard industry and consciousness of the safety production and the weak consciousness of the nonpolluted production, which has resulted in such a serious phenomenon in which the farm-oriented chemical inputs have polluted the environment and the pesticide residue remains on the fruits or the heavy metal exceeds the standard. The third is the imbalanced variety structural ratio, in which the excessive development of a single variety could hardly satisfy the market demand of the diversified consumption but has increased the pressure of marketing. The existence of these problems have been caused because of various reasons, but one of the main reasons should be the lack of 
the effective route to timely obtain the new technology and market information, which has resulted in the backward technology, sluggish information and blind production for the entire orchard producers.

With the continuous improvement of China's comprehensive national strength and the continuous development of the project of "Coverage of Every Village", China's vast countryside has basically realized the entrance of telephone and television into the households in the villages. At the same time, with the rapid development of China's wireless communication project, it is no longer the dream for the better-off orchardists to have their own mobile phones. Telephone and mobile phone have gradually become the tools for the broad grassroots orchardists to learn new knowledge and new technology. Then, it is a problem that should be solved in China's agricultural information technology as to how the agricultural experts or agricultural technology promoters could make full use, in an even more convenient and speedy manner, of these advanced communication tools to pass on the agricultural technology to the orchardists and solve the problems encountered by the orchardists in their production. It is, therefore, of important practical significance in respect to the promotion of China's orchard production to research and use the information technology to solve such problems as of the sluggish dissemination and low dissemination efficiency of the information on the orchard production and set up a bridge of communication between the agricultural experts and the orchardists.

\section{Research on the Mode of the Orchard Production Information Service System}

\subsection{The Main Situation of the Telecom Facilities in Rural Area}

Since our entry into the 21 century, China's government departments at different levels have attached great importance to the construction of the agricultural information network, in which China's 31 provincial-level agricultural departments (exclusive of Hong Kong, Macao and Taiwan) have established their provincial-level agricultural information network platforms and most of the provinces have established their agricultural information centers. Throughout the country, there are more than 2,000 cities and/or counties that have opened up their agricultural information service websites. Until 2010, the agricultural websites have reached 31,108 [4]. China has preliminarily formed an agricultural information network system to cover the whole country.

According to the latest statistical results released by China Internet Network Information Center (CNNIC) in January 2012, up to the end of December 2011, the scale of the Chinese netizens had broken through 500 million and reached 513 million, of which the scale of the rural netizens was 136 million, accounting for $26.5 \%$ of the total netizens [5]. As compared with that in 2006, the rural netizens had increased by 112.89 million and the proportion in the total netizens had gone up to $26.5 \%$ from the $1.6 \%$ in 2006 . This could demonstrate the remarkable increase of the rural residents to approach the Internet. However, as seen from the netizens occupational structure, such netizens as engaged in the agricultural labor accounted 
only for $7.2 \%$ of the total rural netizens (as shown in Figure 1) [6], which was still at a quite low level. It could be seen from it that in addition to the weak consciousness of the Chinese farmers to obtain the information by use of the Internet network, the websites are quite short of such information as being interesting, understandable and learnable for the farmers, and the farmers have quite insufficient means to obtain the website information.

As to how to make a fine job in running such websites as favored by the broad orchardists and at the same time to enable more and more orchardists to obtain the website information and to really make the orchard production technology information enter into the households in the villages, it is the first problem for the current solution to solve the "last kilometer" in the orchard informatization.

Because the per capita annual income in the rural areas is comparatively lower and the ability there to pay for the consumption is limited, the Internet-approaching equipment for the netizens in the rural areas is relatively deficient. However, with the increasing convenience of the mobile phone approaching the Internet, the mobile phone has been favored by the farmers because of its lower price. In 2009, the proportion of the rural netizens to use the desktop computer as the Internetapproaching terminals has declined to $68 \%$, whereas the proportion of the netizens to approach the Internet by use of the mobile phone has seen a rapid increase. At present, China's mobile phone users for the Internet approach have reached 233 million, of which the rural mobile phone users for the Internet approach are about 71.89 million, accounting for $67.3 \%$ of the total rural netizens (as shown in Figure 2) [6]. Since $3 \mathrm{G}$ network has already covered all the county towns and most of the townships throughout the country, the mobile phone has become the mainstream of the Internet-approaching terminals for the rural netizens.

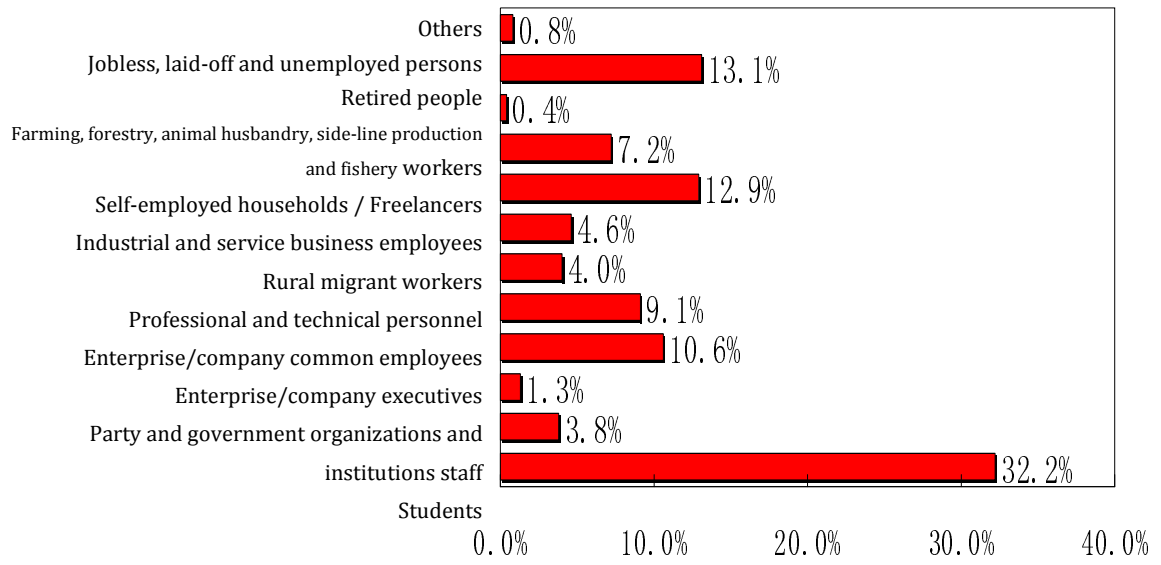

Fig. 1. Rural Netizens Occupational Structure

As shown in the statistical results released by China's Ministry of Industry and Information Technology in January 2011, up to 2010, the whole country's telephone users had totaled 1.15339 billion households, of which the rural telephone users had reached 97.76 million households, with the fixed-line telephone penetration being 
22.1 set/100 people. Among them, the mobile phone users were 859 million and 3G users reached 47.05 million. The mobile phone penetration had reached 64.4 set/100 people, accounting for $74.5 \%$ of the total telephone users and about three times of the fixed-line telephone users. As the rural communication development objectives for the "11th Five-Year Plan" period, the program of "Telephone to Be Connected to Every Village and Internet to Be Approached in Every Township" has been comprehensively realized. Throughout the country, $100 \%$ of the administrative villages have been connected with the telephone, $100 \%$ of the townships have been connected with the Internet (of which $98 \%$ of the townships are connected with the broad band), $94 \%$ of such natural villages as of more than 20 households have been connected with the telephone, and nearly half of the countrywide townships have established the township information service station and county-township-village three-level information service system. China's telecommunication facilities have reached the objective of "entrance into the households in the villages" [7].

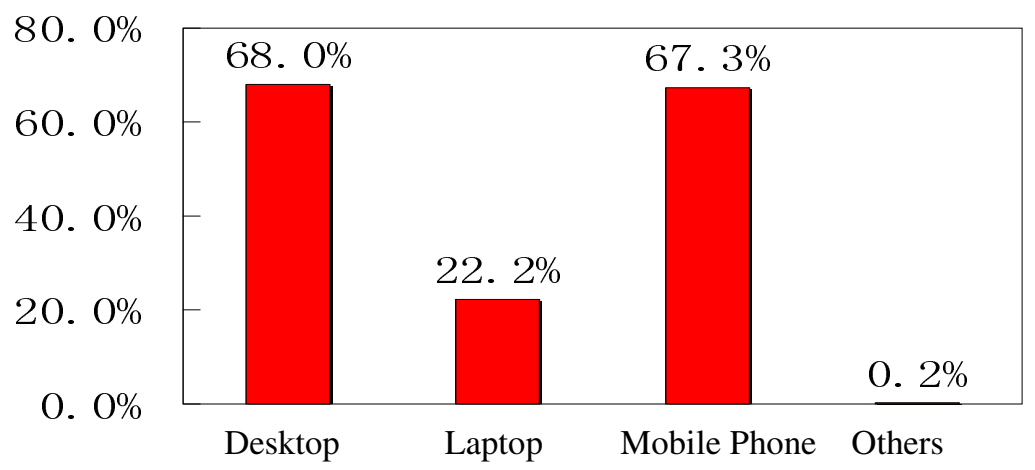

Fig. 2. Rural Netizens Internet-approaching Equipment

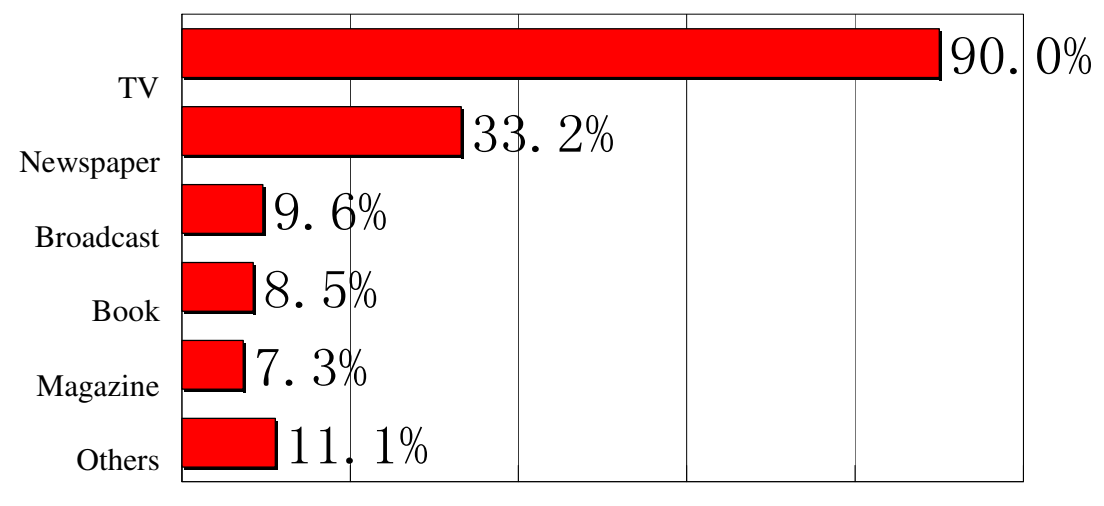

$\begin{array}{lllllll}0.0 \% & 20.0 \% & 40.0 \% & 60.0 \% & 80.0 \% & 100.0 \%\end{array}$

Fig. 3. Main Routes for the Non-Netizens to Obtain Information 
It is discovered from the statistical findings of China Internet Network Information Center that the main route for $88.3 \%$ of the non-netizens to obtain the information is $\mathrm{TV}, 35.9 \%$ of the non-netizens to obtain the information is newspaper, and the proportion of such non-netizens whose main routes to obtain the information are broadcast, book or magazine is not more than 13\% (as shown in Figure 3) [8]. It is thus clear that most of the non-netizens are to obtain the information through the TV.

\subsection{The Architecture of the Fruit Production Information Service System}

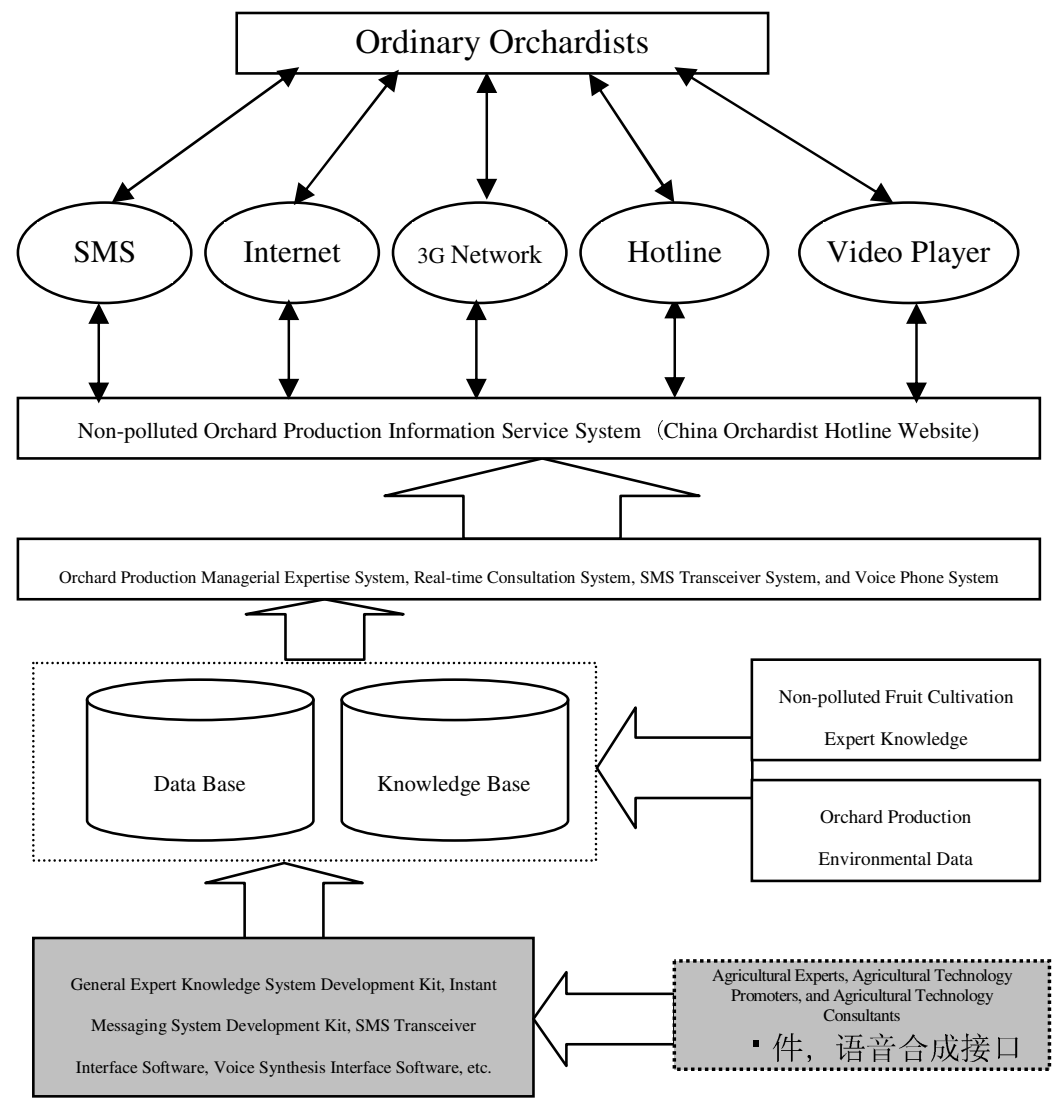

Fig. 4. Structure of the Orchard Production Information Service System

To make full use of China's existing telecommunication facilities and good use of the television and the SMS called as the "Fourth Medium" is the best route to solve the "last kilometer" in the orchard informatization. For this purpose, we have designed such a "Five-in-One" system mode as of the Internet, 3G network, hotline, SMS and video play (as shown in Figure 4). We have developed the networked "Non-polluted Orchard Production Managerial Knowledge System" by the comprehensive use of XML technology, multimedia technology, COM control technology, expert system 
technology and WAP technology. By use of the streaming media processing technology of DirectShow on the WDM device driver model, we have researched and developed the "Instant Messaging Components" and established the "Non-polluted Orchard Remote Real-time Consultation System". We have provided the orchardists with the on-line consultation and the interface to conduct the "one-to-one" on-line communication with the orchardists and orchard experts. Based on the GSM text message transceiver and OCX control and by use of the API functions provided by the GSM module, we have researched and developed the "Non-polluted Orchard Production SMS Transceiver System". And furthermore, by use of CCITT No. 7 signaling, by means of the digital signal processing (DSP) technology and by use of the universal telephone voice player, we have researched and developed the "Nonpolluted Orchard Production Telephone Voice Play System". By use of their mobile phones and/or telephones as the terminals, the farmers could interact with the application on the Internet network and realize the acquisition of information whenever and wherever possible.

\section{Construction of the Non-polluted Orchard Production Managerial Knowledge System}

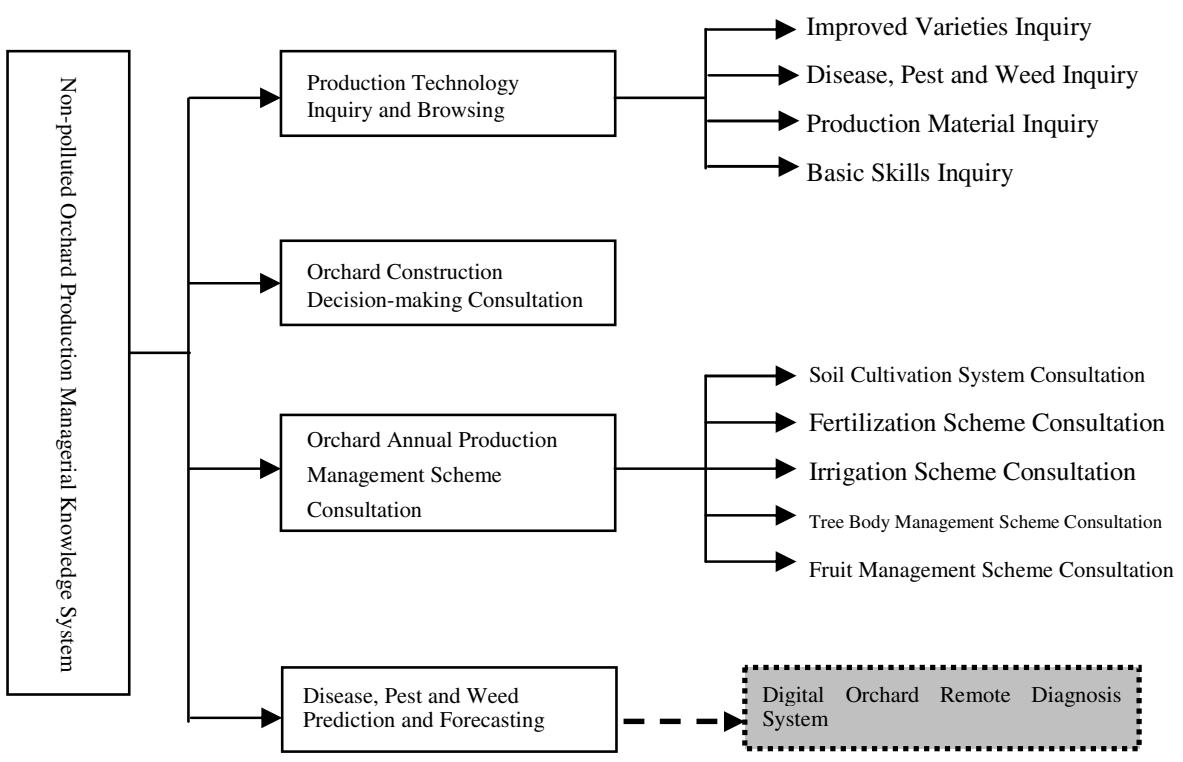

Fig. 5. Functional Diagram of the "Non-polluted Orchard Production Knowledge System"

The Non-polluted Orchard Production Managerial Knowledge System (as shown in Figure 5) includes: Orchard Production Technical Knowledge Browsing Module, Orchard Construction Consultation Module, Orchard Annual Production Management Scheme Consultation Module, and Disease, Pest and Weed Prediction and 
Forecasting Module. Through the Internet or the mobile phone or telephone, the orchardists could directly communicate with the system to inquire any knowledge required to know in the production and any problems that can be solved according to certain rules.

\section{$4 \quad$ Implementation of the System}
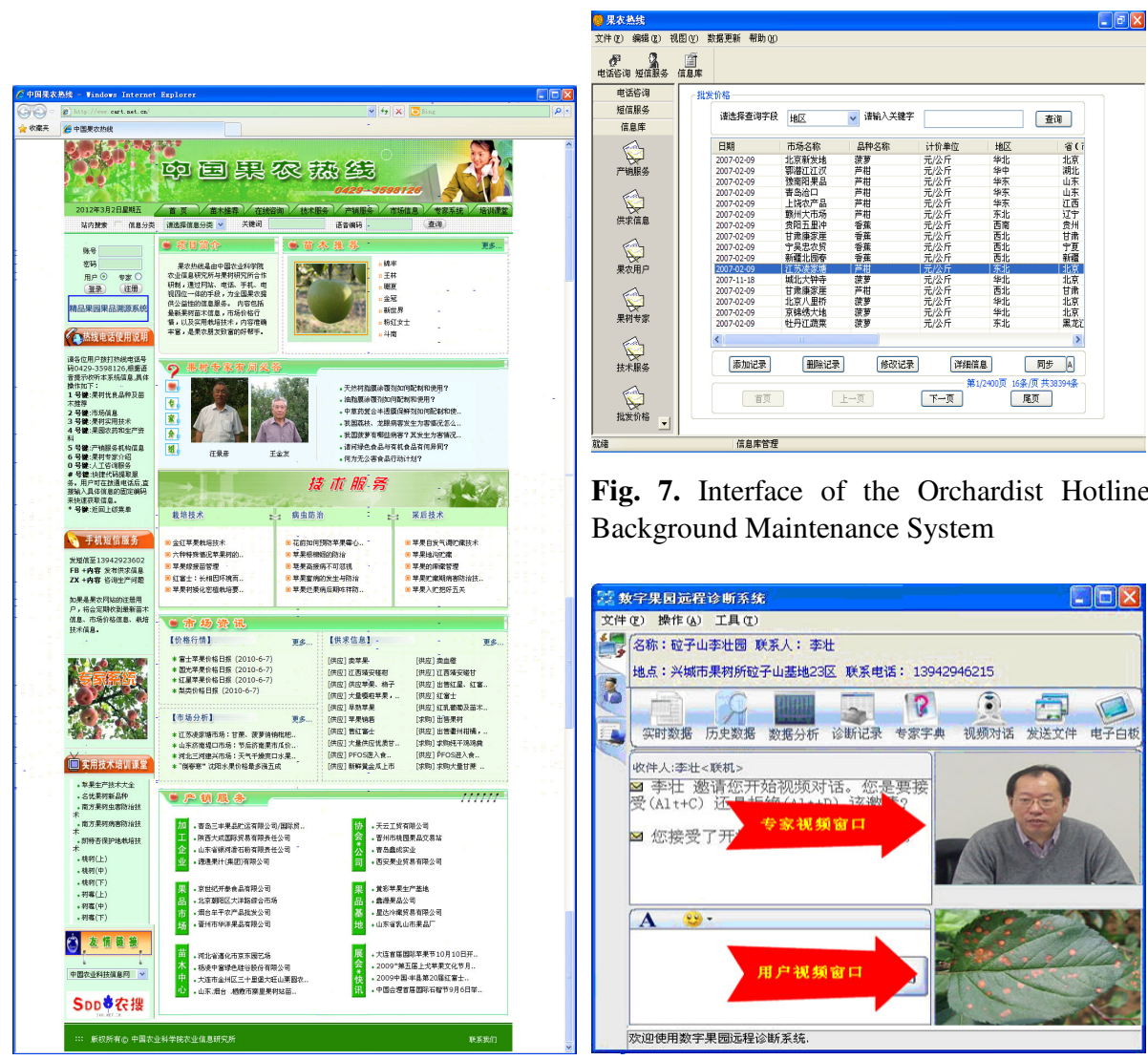

Fig. 7. Interface of the Orchardist Hotline Background Maintenance System

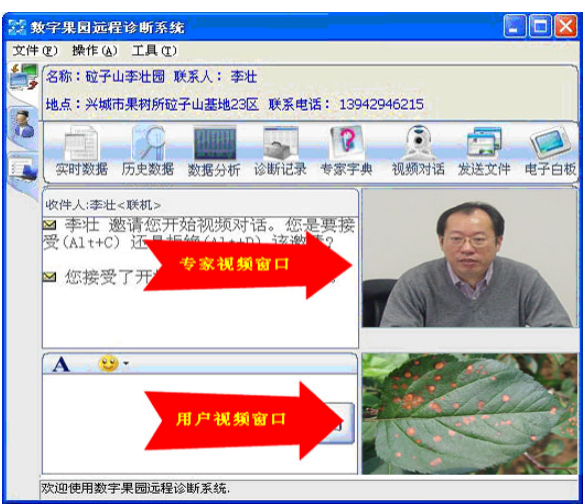

Fig. 6. Interface of China Orchardist Hotline Fig. 8. Interface of the Digital Orchard Website

Remote Diagnosis System

The "Three Networks in One" Orchard Production Information Service System consists of such three parts as of China Orchardist Hotline Website (as shown in Figure 6), Orchardist Hotline Background Maintenance System (as shown in Figure 7) and Digital Orchard Remote Diagnosis System (as shown in Figure 8). 


\subsection{China Orchardist Hotline Website}

China Orchardist Hotline Website (http://www.cart.net.cn/) is the web portal of the "Orchard Production Information Service System" on the Internet. (As for the Android-edition mobile phone users, please visit http://android.cart.net.cn, but for the wap-edition mobile phone users, please visit http://wap. cart.net.cn.) The Website has integrated the "Non-polluted Orchard Production Managerial Knowledge System", "Apple Tree Plant Diseases and Insect Pests Expert System" and "Digital Orchard Remote Diagnosis System" to provide the information service of public benefit for the orchardists throughout the country. The Website includes such columns as of the recommendation of the latest fruit trees and nursery stock, recommendation of competitive orchard, practical cultivation technique, market price quotes, as well as the expert on-line consultation, expert system and training classroom.

\subsection{Orchardist Hotline Background Maintenance System}

By use of the $\mathrm{C} / \mathrm{S}$ structure, programmed with the $\mathrm{C}++$ Builder language and working in the environment of Windows Operating System, the Orchardist Hotline Background Maintenance System is composed of such three parts as of telephone consultation, SMS and information base maintenance. (1) Telephone Consultation and Audio Service: It consists of such four modules as of telephone attendance, running conditions statistics, broadcasting list maintenance and voice base maintenance. (2) SMS: It includes such five parts as of text message receiving, draft mailbox, text message en route, text message sent and user address list maintenance. (3) Information Base Maintenance: This module is a background maintenance for the database of China Orchardist Hotline Website, which contains such functions as of the addition, modification, deletion and details viewing for the data set of each database, and is at the same time characterized by the data synchronization, which means to make the database of the server synchronous with the data on the customer terminals so as to realize the release on the Website of the data maintained by the agricultural experts (or agricultural technology consultant).

\subsection{Digital Orchard Remote Diagnosis System}

By use of the B/S structure, the Digital Orchard Remote Diagnosis System consists of such three parts as of the remote consultation, video conference and knowledge inference. (1) Remote Consultation: It contains such functions as of the image-text communication, video consultation, document transmission, electronic whiteboard, viewing and analysis of the information on the orchard cultivation environment. (2) Video Conference: It is designed to provide the real-time on-line consultation function for the experts and orchardists through the construction of the virtual video conference room. (3) Expert System: It is designed to collate the experts' experience and knowledge to form a knowledge inference machine, so as to solve, in the limited steps, the problems that the orchardists may encounter. 


\section{Conclusion}

At present, the "Three Networks in One" Orchard Production Information Service System is mainly applied in Xingcheng and Suizhong of Liaoning Province and the outer suburbs of Beijing. This System has linked the wireless communication network, fixed-line telephone network and the Internet network together to realize the seamless bridging of information, so as to broaden the service scope of the application system on the internetwork. It has closely connected the experts of the Institute of Pomology (IP) of the Chinese Academy of Agricultural Sciences (CAAS) with the orchardists in the promotion pilot zone to realize the "all-weather" information service for the orchardists, which is greatly welcome by the orchardists in the promotion pilot zone. It has realized the rapid promotion in a large area of the orchard new technology, so as to provide the convenient means of decision-making and management for the grassroots technical personnel and broad orchardists in the nonpolluted orchard production. It has realized the universality and foolproof of the nonpolluted orchard production technology, so as to make it be visible, tangible and usable for the broad orchardists and become the "stationed orchard senior expert" in the orchard zone. All of these have fundamentally improved the technical level of the broad orchard producers and made up such a series of malpractice as resulted from the imperfection of the orchard technology promotion system and the shortage of the orchard technical personnel, so that the "problem of last kilometer" in the dissemination of orchard information has been effectively solved.

Acknowledgments. The Orchard Production Information Service System has been accomplished in the support of the National High-Tech (863) Program's Project of "Remote Intelligent Diagnosis System for the Field Crop Plant Diseases and Insect Pests (2007 AA10Z237)" and the Agricultural Research Findings Commercialized Project of "Remote Diagnosis System for the Orchard Plant Diseases and Insect Pests and Its Pre-production (2009 GB23260457)", for which we would like to extend our heartfelt thanks.

\section{References}

1. China Agricultural Information.Network. China's Fruit Production Situation over the Years http://www.agri.gov.cn/V20/cxl/sjfw/tj.sj/sg_1/scqk/ 历年水果生产情况. html.

2. China Agriculture Press. China Agricultural Yearbook (2010)

3. Wang, L.: An Analysis on China's International Competitiveness in Fruits. Agricultural Economy (04), 28 (2011)

4. Ministry of Agriculture of the People's Republic of China.China's Development Report on Agricultural and Rural Informatization (2010), http://www.moa.gov.cn/ztzl/ sewgh / fzbg/201112/P020111208362702958871.pdf

5. China Internet Network Information Center. China's Statistical Report on the Internet Network Development Situation (1) (2012), http://www.cnnic.net.cn/dtygg/ dtgg/201201/W020120116337628870651.pdf 
6. China Internet Network Information Center. China's Investigation Report on the Rural Internet Development Situation in (2009),

http://www.cnnic.cn/dtygg/dtgg/201004/t20100415_13712.html

7. Ministry of Industry and Information Technology of the People's Republic of China. China's National Statistical Bulletin on the Telecommunications Industry in (2010), http: / /www.miit.gov.cn/n11293472/n11293832/n11294132/ n12858447/13578942.html

8. China Internet Network Information Center. China's Statistical Report on the Internet Network Development Situation (1) (2007),

http: / /www. cnnic.net.cn/uploadfiles/doc/2007/1/22/212245.doc 